\title{
Effects of Additional Use of Bioactive Glasses or a Hydroxyapatite Toothpaste on Remineralization of Artificial Lesions in vitro
}

\author{
Philipp Körner ${ }^{\mathrm{a}} \quad$ Jana A Schleich $^{\mathrm{a}}$ Daniel B. Wiedemeier ${ }^{\mathrm{b}}$ Thomas Attin $^{\mathrm{a}}$ \\ Florian J. Wegehaupt ${ }^{a}$ \\ ${ }^{a}$ Clinic of Conservative and Preventive Dentistry, Center of Dental Medicine, University of Zurich,

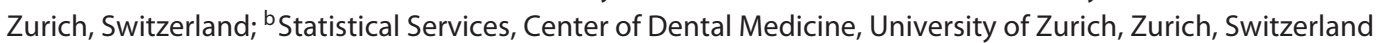

\section{Keywords}

Caries $\cdot$ Remineralization $\cdot$ Hydroxyapatite $\cdot$ Bioactive glass $\cdot$ Toothpaste

\begin{abstract}
Objectives: This in vitro study aimed to evaluate and compare the effect of two different bioactive glasses, a hydroxyapatite-containing, fluoride-free toothpaste (HTP) and a fluoride toothpaste (FTP) on the remineralization behavior of initial caries lesions. Materials and Methods: A total of 100 bovine enamel samples were randomly allocated to five groups of 20 samples each: NC = negative control group (artificial saliva); HTP = HTP group (Karex); FTP = FTP group (EImex caries protection, 1,400 ppm); FTP + BG $_{\text {nano }}=$ FTP followed by Actimins bioactive glass; FTP $+\mathrm{BG}_{\text {amorph }}=$ FTP followed bySchottbioactiveglass. Radiographicdocumentation (advanced transversal microradiography; aTMR) was applied before and after all samples were exposed to a demineralizing gel for 10 days. Over a period of 28 days, samples were covered twice a day (every $12 \mathrm{~h}$ ) with a toothpaste slurry of the respective test group or with artificial saliva in NC for 60 $\mathrm{s}$ and brushed with 15 brushing strokes. Samples in FTP + $B G_{\text {nano }}$ and $F T P+B G_{\text {amorph }}$ were additionally treated with the respective bioactive glass slurry for $30 \mathrm{~s}$ after brushing with the FTP. In the meantime, all samples were stored in artificial
\end{abstract}

karger@karger.com www.karger.com/cre

Karger $\stackrel{\text { ' }}{5}$

GOPEN ACCESS
(C) 2020 The Author(s)

Published by S. Karger AG, Basel

This is an Open Access article licensed under the Creative Commons Attribution-NonCommercial-4.0 International License (CC BY-NC) (http://www.karger.com/Services/OpenAccessLicense), applicable to the online version of the article only. Usage and distribution for commercial purposes requires written permission. saliva. After 28 days, the structure of all samples was assessed again using aTMR and compared to the values measured after demineralization. The statistical evaluation of the integrated mineral loss was performed using Kruskal-Wallis test followed by a post hoc Conover test. Results: The FTP revealed the significantly highest increase of mineral content while the HTP showed the significantly lowest remineralization. Compared to artificial saliva, the use of the HTP or the combined application of FTP followed by bioactive glasses (FTP $+B_{\text {nano }}$ and FTP $+B_{\text {amorph }}$ ) showed no significant remineralization. Conclusion: Under remineralizing in vitro conditions, brushing with 1,400 ppm FTP induced significantly more remineralization compared to storage in artificial saliva. The additional administration of both bioactive glasses as well as the substitutional brushing with an HTP resulted in significantly less remineralization compared to brushing with 1,400 ppm FTP. @ 2020 The Author(s)

Published by S. Karger AG, Basel

\section{Introduction}

Although the prevalence of caries has drastically declined over the past decades, it is still one of the most common diseases worldwide [Lagerweij and van Loveren, 2015]. Dental enamel does not have a regenerative capac- 
Fig. 1. Study design.

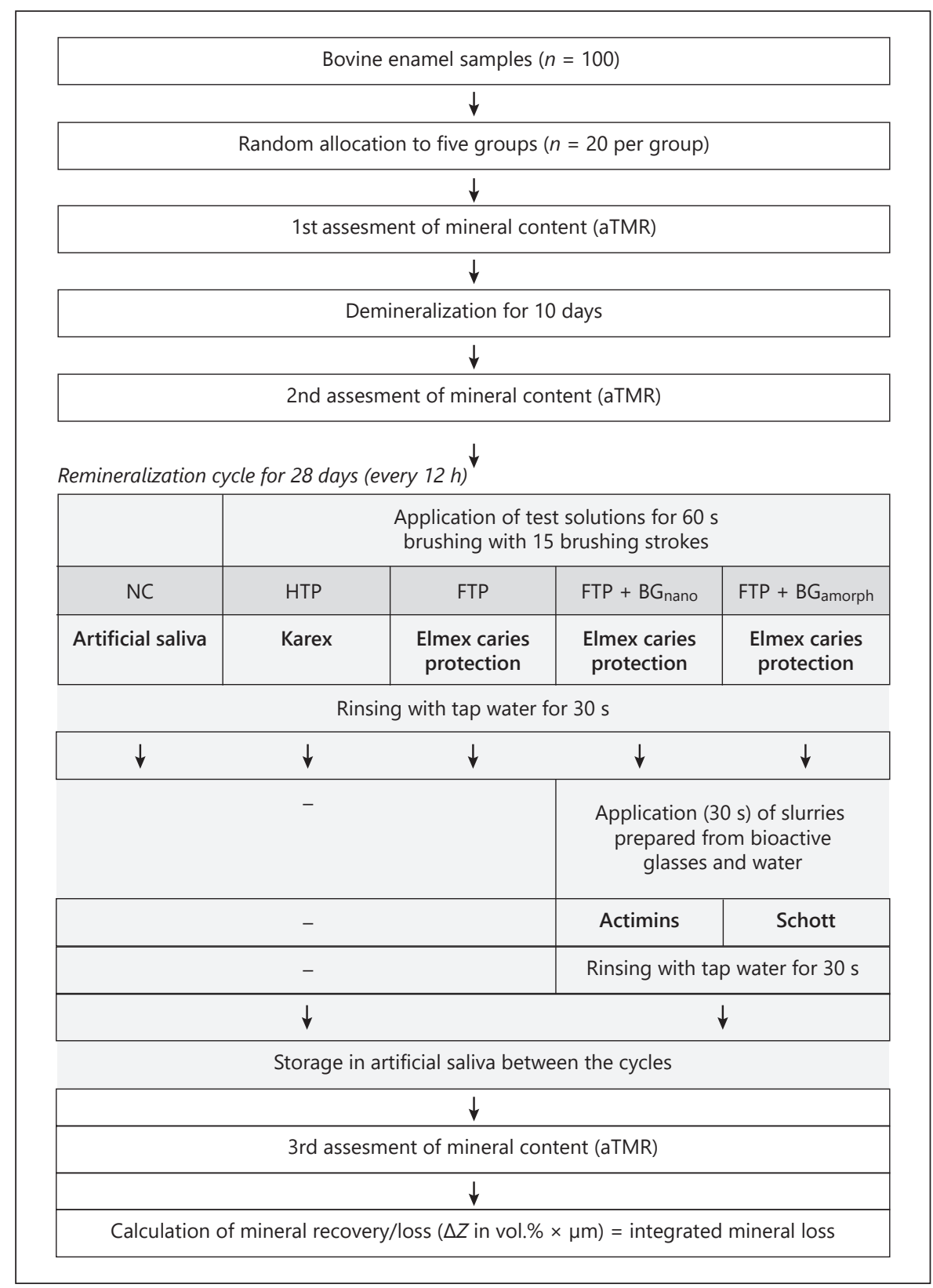

ity after tooth eruption and caries lesions may occur at any time in the course of a lifetime [Selwitz et al., 2007]. Thus, the focus of modern dentistry should be the protection and preservation of dental hard tissues. In this context, a reduction of caries risk, the detection of tooth disease in an early stage, and a preferably non-invasive approach are important factors in preventive dentistry [Wegehaupt et al., 2012]. A potentially non-invasive approach is the remineralization of initial caries lesions which can be supported by different substances. Beside established fluo- ride-containing oral health care products, further approaches and products are discussed and evaluated in the current literature. For example, bioactive glasses composed from silicon dioxide, disodium oxide, calcium oxide, and phosphorus pentoxide have been used in dentistry in the course of implantology, periodontal bone regeneration, or treatment of dentin hypersensitivities [Hench, 2006]. They were shown to enable an in vivo response, including osteoconductivity, adherence to bone by the release of ions, and the potential to form an apatite 
layer [Hench, 1991], and have been reported to induce mineralization of dentin surfaces [Forsback et al., 2004]. However, little is known and described in the literature about the potential of bioactive glasses to promote remineralization of initial enamel caries lesions [Li et al., 2014]. Another approach is the remineralization of initial enamel lesions using artificial hydroxyapatite minerals which are seemingly analogous to natural enamel [Enax and Epple, 2018]. The artificial minerals aim to reinforce partially destroyed hydroxyapatite crystals in enamel through accumulation and incorporation of calcium and phosphate ions. While in some studies hydroxyapatite-containing toothpastes were shown to enable a remineralizing potential [Makeeva et al., 2016; Meyer et al., 2018], other studies could not find a remineralizing effect for hydroxyapatite [Zhang et al., 2015; Esteves-Oliveira et al., 2017] or report missing evidence [Hellwig et al., 2018]. In this context, the microcrystalline hydroxyapatite-containing toothpaste Karex has recently been brought to market and promises caries protection without the use of fluoride. However, there are few studies investigating its remineralizing potential on initial enamel lesions [Schlagenhauf et al., 2019].

Therefore, the aim of the present in vitro study was to determine the remineralizing potentials of either a fluoride toothpaste (FTP) followed by two different kinds of bioactive glasses, or a hydroxyapatite containing, fluoride-free toothpaste (HTP) on initial enamel caries lesions and compare them to an FTP only. The hypothesis was that there is no significant difference in the mineral content of samples with initial caries lesions after treating them with an FTP, a combination of an FTP followed by a bioactive glass (Actimins or Schott bioactive glass), an HTP, or solely with artificial saliva.

\section{Materials and Methods}

The study design is illustrated in Figure 1.

\section{Sample Preparation and Allocation}

A total of 100 samples were gained from bovine incisors and cut transversal to the buccal surface into parallel enamel samples with $500 \mu \mathrm{m}$ thickness using a water-cooled saw microtome (SP1600, Leica Microsystems AG; Heerbrugg, Switzerland). Each sample was placed between two polycarbonate platelets (Makrolon, Bayer AG; Darmstadt, Germany), embedded in a light curing resin (LC Block-Out Resin, Ultradent Products Inc.; South Jordan, UT, USA) and light polymerized for $30 \mathrm{~s}$ (Bluephase Polywave, Ivoclar Vivadent AG; Schaan, Liechtenstein). Afterwards, enamel surfaces were standardized and ground flat using a mill (BFW 40/E, Proxxon; Foehren, Germany) with a $25-\mu \mathrm{m}$ diamond burr (Finierer NR 840, Busch \& Co. KG; Engelskirchen, Germany). In this course, the outer cementum and enamel layer was removed.

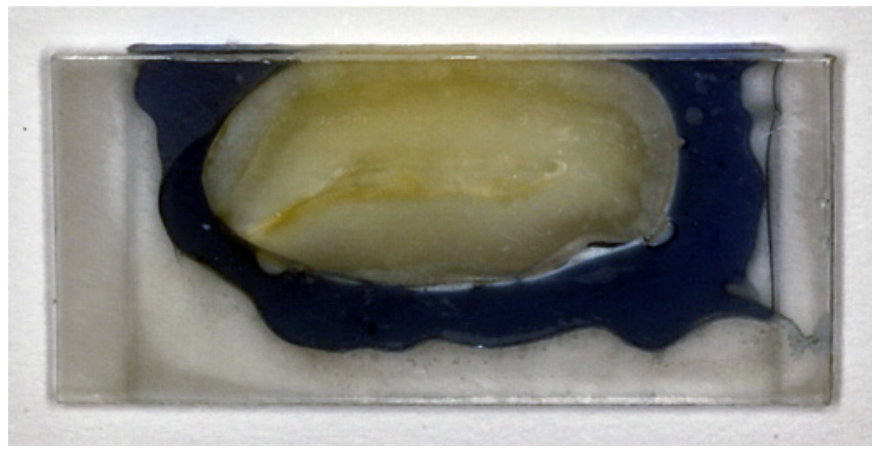

Fig. 2. Enamel sample placed between two polycarbonate platelets and embedded in a light-curing resin.

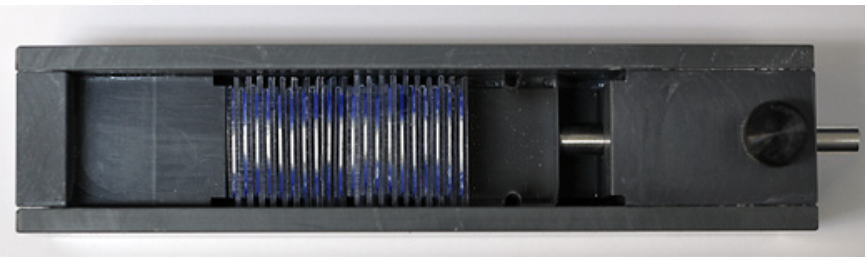

Fig. 3. Custom-made holding devices able to carry all 20 samples of the respective group.

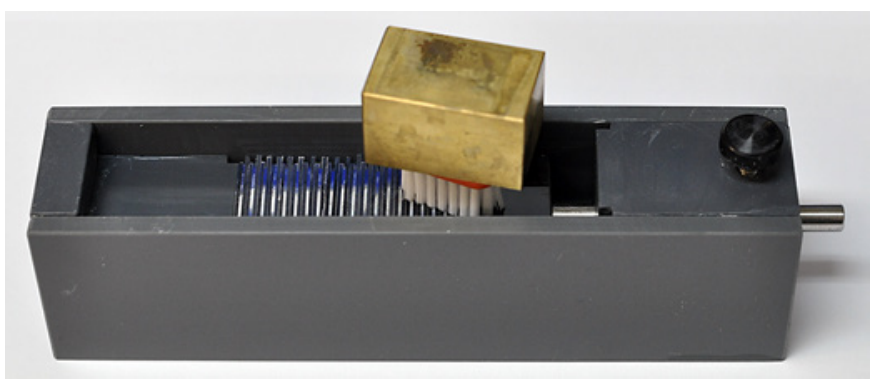

Fig. 4. The 100-g weight placed on the head of a toothbrush to enable a constant brushing force.

An exemplary sample is illustrated in Figure 2. All 100 prepared samples were randomly assigned into five groups of 20 samples each, labeled and placed in one of five custom-made holding devices able to carry all 20 samples of the respective group (Fig. 3). During the process of preparation and until use, all samples were stored in non-fluoridated tap water.

\section{Demineralization}

Before demineralization, the mineral content of all samples was assessed using advanced transversal microradiography (aTMR; see Mineral Analysis). Artificial initial enamel lesions were created using both a demineralizing gel and a demineralizing solution based on a thymol stock solution with lactic acid and calcium concentrate with a defined $\mathrm{pH}$ value of 4.4. The demineralization protocol is described by Amaechi et al. [1998]. After 10 days of demineralization, a mean lesion depth of $118.1 \pm 20.2 \mu \mathrm{m}$ was measured. 


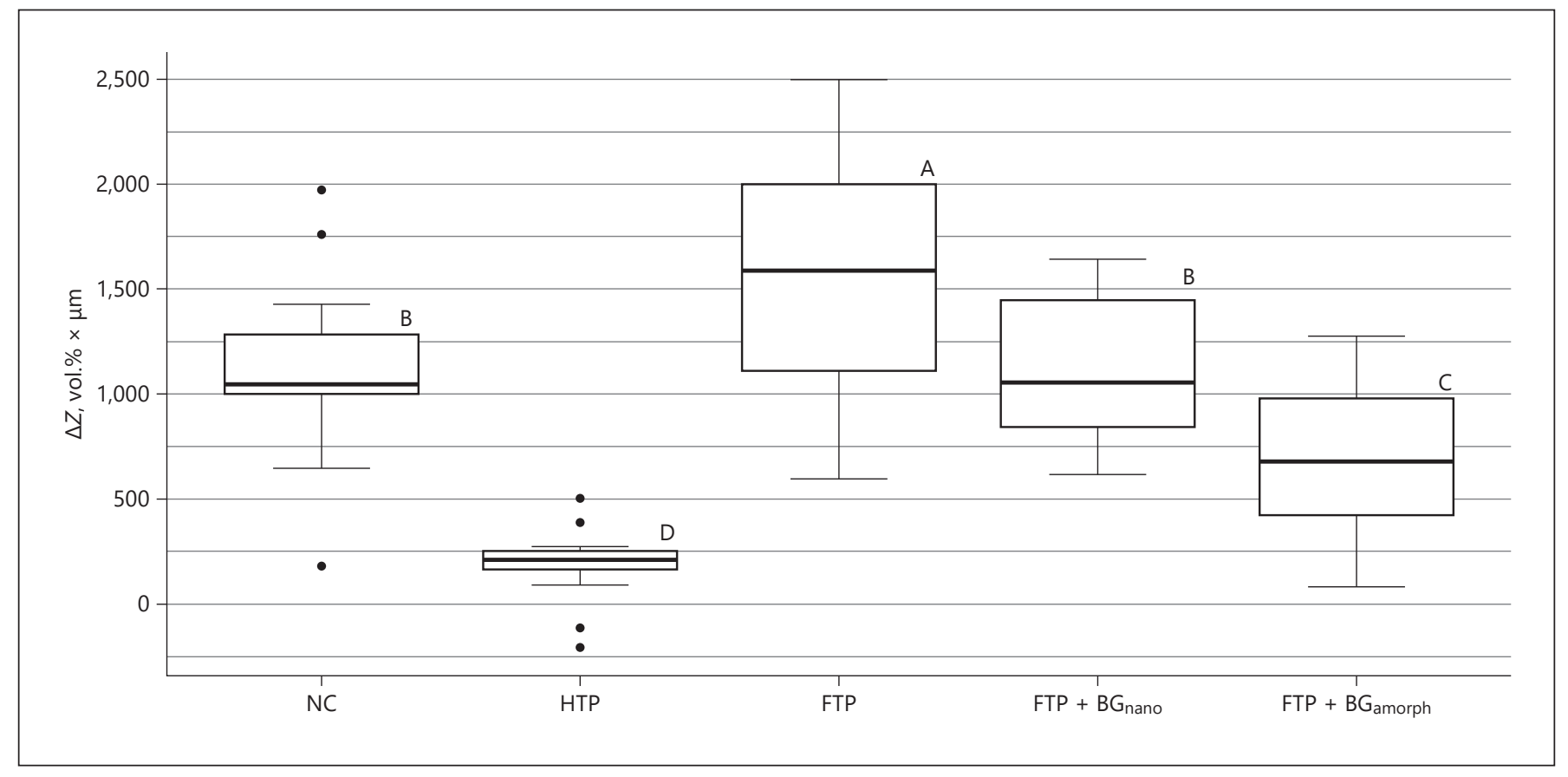

Fig. 5. Boxplot of the difference of integrated mineral loss (vol. $\% \times \mu \mathrm{m})$ in the five test groups (NC, HTP, FTP, $\left.\mathrm{FTP}+\mathrm{BG}_{\text {nano }}, \mathrm{FTP}+\mathrm{BG}_{\text {amorph }}\right)$. The higher the difference in integrated mineral loss, the more remineralization took place. The horizontal line in the box represents the median value, the box represents the 25 and 75 th percentiles, and whiskers represent the 5 and 95th percentiles. Significantly different values are marked with different capital letters.

\section{Remineralization Procedure}

For a period of 28 days, the samples were covered twice a day (every $12 \mathrm{~h}$ ) with a group-specific toothpaste slurry (mix of toothpaste and artificial saliva at a weight ratio of 1:2; HTP [Karex, Dr. Kurt Wolff GmbH; Bielefeld, Germany]; FTP, FTP $+\mathrm{BG}_{\text {nano, }}$ and $\mathrm{FTP}+\mathrm{BG}_{\text {amorph }}$ [Elmex caries protection, GABA; Therwil, Switzerland]), or with artificial saliva (negative control; NC) for $60 \mathrm{~s}$ and brushed with 15 brushing strokes (1 stroke/s; Paro S39, Esro AG; Kilchberg, Switzerland). A constant brushing force of about $1.0 \mathrm{~N}$ was applied by fixing a $100-\mathrm{g}$ weight on the head of the toothbrush (Fig. 4). After brushing with the FTP slurry and rinsing with tap water for $30 \mathrm{~s}$, samples of FTP $+\mathrm{BG}_{\text {nano }}$ and $\mathrm{FTP}+\mathrm{BG}_{\mathrm{amorph}}$ were additionally treated with slurries prepared from the respective bioactive glasses and tap water (weight ratio 2:1) for $30 \mathrm{~s}$. The bioactive glass in FTP $+\mathrm{BG}_{\text {nano }}$ (Actimins Dental Desensitizer, Datsing Bio-Tech Co.; Beijing, China) is a commercially available dental product and claims to contain bioactive nanocrystal powder mainly composed of calcium, phosphorus, sodium, and silicon.

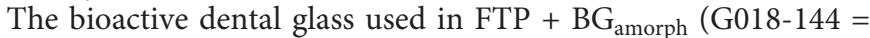
45S5, Schott AG; Landshut, Germany) is a typical amorphous bioactive glass (grain size SM $4.0=\mathrm{d}_{50}=4.0 \pm 1.0 \mu \mathrm{m}$ ) composed of the four inorganic oxides $\mathrm{SiO}_{2}, \mathrm{CaO}, \mathrm{Na}_{2} \mathrm{O}$, and $\mathrm{P}_{2} \mathrm{O}_{5}$.

Between treatments, all samples were stored in daily refreshed artificial saliva ( $\mathrm{pH}$ 6.5) which was formulated according to Klimek et al. [1982] but without D-glucose $\left(\mathrm{C}_{6} \mathrm{H}_{12} \mathrm{O}_{6}\right)$ and ascorbic acid $\left(\mathrm{C}_{6} \mathrm{H}_{8} \mathrm{O}_{6}\right)$. The toothpaste and bioactive glass slurries were renewed every $48 \mathrm{~h}$. After 28 days the mineral content of all samples was assessed again.

Remineralization with Hydroxyapatite or Bioactive Glass

\section{Mineral Analysis}

For mineral analysis, the quantitative assessment of mineral content in calcified tissues was performed using aTMR as recently described by Becker et al. [2020]. Mineral uptake/loss was assessed by calculating the difference $(\Delta \mathrm{Z}$ in vol. $\% \times \mu \mathrm{m})$ between the respective surface before and after remineralization (integrated mineral loss).

\section{Statistical Analysis}

The dataset was analyzed using the software R [R Core Team, 2015] and the associated packages ggplot2 [Wickham, 2016] and PMCMR [Pohlert, 2014]. Due to deviations in homogeneity of variance for the measurement after 28 days, a non-parametric test (Kruskal-Wallis), followed by a post hoc Conover test was computed to check for differences between the five test groups. Additionally, corrections for multiple testing were made using the Bonferroni-Holm method. The level of significance was set at 5\%.

\section{Results}

After 10 days of demineralization each of the 100 samples showed caries-like lesions with relatively high mineralized outer surfaces compared to the demineralized subsurface lesions. The mean lesion depth was $118.1 \pm$ $20.2 \mu \mathrm{m}$ and the mean integrated mineral loss 3,055.6 \pm 
632.7 vol. $\% \times \mu \mathrm{m}$. There were no significant differences between the groups. Within the groups, mineral loss ranged from $2,915.5 \pm 716.7$ to $3,354.1 \pm 409.1$ vol. $\% \times$ $\mu \mathrm{m}$. The difference of integrated mineral loss $(\Delta \mathrm{Z}$ in vol.\% $\times \mu \mathrm{m})$ between the baseline measurement ( $\triangle$ ZBaseline in vol. $\% \times \mu \mathrm{m})$ and measurement after 28 days $(\Delta$ ZRemin in vol. $\% \times \mu \mathrm{m}$ ) for all five test groups is illustrated in Figure 5.

The FTP revealed the significantly highest increase of mineral content $(p<0.05)$ overall, and also showed significantly higher remineralization than artificial saliva (NC). The HTP showed the significantly lowest remineralization $(p<0.05)$. Compared to the NC, no significant remineralization could be achieved using the HTP or the combined application of FTP followed by bioactive glasses $\left(\mathrm{FTP}+\mathrm{BG}_{\text {nano }}\right.$ and $\left.\mathrm{FTP}+\mathrm{BG}_{\text {amorph }}\right)$.

\section{Discussion}

The present in vitro study revealed significant differences between the test groups in terms of the remineralization potential of initial caries lesions, leading to the denial of the hypothesis. The FTP showed the significantly highest increase of mineral content after 28 days and the HTP the lowest. The combined application of FTP followed by the respective bioactive glasses revealed no significantly higher remineralization compared to the control group.

Enamel samples in this study were prepared from bovine incisors which have been used and discussed in multiple studies investigating demineralized dental hard tissues and can be regarded as a suitable substitute for human enamel [Kielbassa et al., 2001]. Artificial caries lesions were created according to an established demineralization protocol by Amaechi et al. [1998] with additional thymol which was added for antibacterial reasons. The mean lesion depth in this study $(118.1 \pm 20.2 \mu \mathrm{m})$ was in the range of most in vitro and in situ studies investigating the de- and remineralization of teeth $(50-150 \mu \mathrm{m})$ [White, 1995]. The quantity (twice per day) and duration (60 s) of toothbrushing, as well as the amount $(n=15)$, frequency ( 1 stroke/s), and application force $(1 \mathrm{~N})$ of the performed brushing strokes aimed to simulate realistic in situ conditions. However, it should be mentioned that no biofilm had to be removed in this model, thus brushing was only performed to apply the tested agents. Furthermore, it has to be considered that the storage of samples in artificial saliva between the brushing periods is not able to adequately imitate the intraoral mineralizing processes
[White, 1995]. Remineralization in vitro is likely to be greater than in vivo as proteins (e.g., statherin) in natural human saliva bind calcium and thus inhibit calcium phosphate precipitation [Shellis et al., 2011]. Other modifying factors such as pellicle formation, bacteria, and fluoride in saliva and plaque fluid were not regarded in this study. Furthermore, it has to be considered that compared to a $\mathrm{pH}$-cycling model, the study design does not adequately reflect the dynamic process of caries progression with alternating phases of de- and remineralization. Thus, this study can provide information about the remineralizing potential of the used products, but not about caries-inhibiting properties. As products claiming to enable remineralization should be capable of inducing remineralization in a net-remineralizing in vitro model, this study has to be regarded as an initial investigation. Agents enabling net remineralization can then be investigated in a model with periodic $\mathrm{pH}$ changes (simulating net re- and net demineralizing conditions) as a next step.

TMR is commonly used for mineral analysis of calcified tissues and assessment of change in the mineral content of enamel samples [Gmür et al., 2006]. The advanced technique as recently described by Becker et al. [2020] was used in this study as it enables even more precise and reliable analyses in combination with facilitated sample preparation and test procedures.

The significantly highest increase of mineral content was observed for the FTP (1,400 ppm). In a review of the literature [Li et al., 2014] as well as in other studies [Lippert and Juthani, 2015; Wierichs et al., 2017] investigating the remineralization of enamel, likewise pronounced remineralizing effects of fluoride are described which can mainly be attributed to a precipitation of apatite crystals in enamel. The effects of fluoride on the oral cavity and the entire human organism are well known and investigated [Buzalaf and Whitford, 2011; Buzalaf et al., 2011]. Therefore, current guidelines consistently recommend fluoridation of initially demineralized enamel to enhance remineralization [Geurtsen et al., 2016]. Several studies demonstrated that the effect of fluoride agents might be increased by reducing their $\mathrm{pH}$ [Brighenti et al., 2006; Alves et al., 2007; Yamazaki and Margolis, 2008]. The adsorption of mineral ions into the lesion increases with decreasing $\mathrm{pH}$. Thus, the remineralizing effect of acidic agents is supposed to be significantly higher than the effect observed for neutral agents [Yamazaki and Margolis, 2008]. The FTP used in this study is acidic, whereas the HTP (Karex) seems to be neutral. Potentially, this fact might have influenced the results and contributed to the significantly lowest remineralizing potential of the inves- 
tigated micro-crystalline HTP. Still, it has to be considered that in vivo saliva might buffer the low $\mathrm{pH}$ of an acidic toothpaste, potentially alleviating this effect.

Different studies describe ambivalent effects of microhydroxyapatite on the remineralizing potential of demineralized enamel [Li et al., 2008; Huang et al., 2011; Schlagenhauf et al., 2019]. At the same time, other studies report a significant remineralizing effect for nanohydroxyapatite [Huang et al., 2010; Makeeva et al., 2016; Manchery et al., 2019]. In general, it has to be taken into consideration that little is known about the interaction of applied hydroxyapatite minerals with dental hard tissues and, to this day, it has not been conclusively clarified whether a desired remineralizing or inhibiting effect on caries, erosion, or plaque can be achieved using this active substance [Hellwig et al., 2018]. Possibly, there might be differences in the effect mechanism related to the size of hydroxyapatite particles [Li et al., 2008]. An in vitro study showed that nano-hydroxyapatite enables remineralization of demineralized enamel while no difference could be observed between the NC (water) and micro-hydroxyapatite [Huang et al., 2011]. The investigated toothpaste in this study contains micro-hydroxyapatite. It might be suspected that the micro-hydroxyapatite particles are less able to penetrate the lesion body of demineralized enamel but at the same time might form a sealing deposition on the porous surface, limiting the diffusion and accumulation of salivary minerals in the lesion and thus hampering remineralization. This would explain the lowest measured remineralizing potential in this study, which was even lower than the one in the control group where only artificial saliva was applied.

The Schott bioactive glass is a typical amorphous bioactive glass and claims to have a remineralizing and strengthening effect on human hard tissue and to be beneficial for the treatment of acid-caused enamel erosion by releasing ions able to form a mineral matrix equivalent to that of hydroxyapatite. The Actimins bioactive glass seems to exhibit $\mathrm{SiO}_{2}$ as the crystalline phase and contains bioactive nanocrystal powder. Beside functioning as a desensitizer, Actimins claims to promote dental remineralization by raising the intraoral $\mathrm{pH}$ value to facilitate the formation of hydroxyapatite by releasing minerals (silica, calcium, phosphorous) and by crystalizing an emerged calcium and phosphate layer into carbonated hydroxyapatite. A significant increase of enamel surface hardness could be observed in vitro for specimens treated with bioactive glasses [Milly et al., 2014]. However, the glasses seem not to be able to reduce lesion depth. It is rather assumed that the precipitation of calcium und phosphate is confined to outer surface layers [Milly et al., 2014]. Furthermore, it has to be considered that the interaction of calcium, phosphate, and fluoride might result in precipitation of ions leading to a reduced amount of minerals for remineralization on the one hand and a limited diffusion of minerals into the lesion depth caused by precipitate accumulation on the lesion surface on the other [Wefel, 2009]. The results of this study seem to confirm this assumption as in the bioactive glass-containing groups significantly less remineralization was observed compared to the group in which solely the FTP was applied. Still, it should be kept in mind that the additional application procedure of the bioactive glass slurry in the FTP + $\mathrm{BG}_{\text {nano }}$ and $\mathrm{FTP}+\mathrm{BG}_{\text {amorph }}$ groups compared to no further intervention in the NC, HTP, and FTP groups might be a potential bias.

Clearly, further in vitro and in vivo studies, especially investigating bioactive glasses, are needed in order to gain better knowledge and understanding about the different influence factors and their effects on initial caries lesions. Especially $\mathrm{pH}$-cycling protocols should be included, and to further understand the mode of action of bioglasses the release of relevant active ions should be determined.

\section{Conclusion}

Within the limitations of this study the following conclusions can be drawn after 28 days of testing under remineralizing in vitro conditions:

1. Brushing with 1,400 ppm FTP enabled significantly more remineralization compared to storage in artificial saliva.

2. The application of bioactive glasses in addition to $1,400 \mathrm{ppm}$ FTP resulted in significantly less remineralization compared to brushing only with the 1,400 ppm FTP.

3. Brushing with the micro-HTP showed significantly less remineralization than brushing with $1,400 \mathrm{ppm}$ FTP.

Therefore, affected patients with initial caries lesions should rather choose an FTP instead of the other tested toothpaste systems.

\section{Acknowledgements}

The current study is part of and in parts identical to the doctor's thesis "Remineralisation initialer kariöser Läsionen mit Hydroxylapatit oder Bioglas" by J. Schleich, based at the University of Zurich, Switzerland, under the supervision of Prof. T. Attin. 


\section{Statement of Ethics}

The study required no ethical approval. Bovine teeth were received as a byproduct from a local slaughterhouse in Zurich.

\section{Conflict of Interest Statement}

The authors declare no potential conflicts of interest with respect to the authorship and publication of this article.

\section{Author Contributions}

Philipp Körner: wrote the manuscript. Jana A. Schleich: performed the clinical experiment, wrote the doctor's thesis, and proofread the manuscript. Daniel B. Wiedemeier: performed the statistical evaluation and proofread the manuscript. Thomas Attin: research idea, contributed substantially to discussion and writing of the paper, and proofread the manuscript. Florian J. Wegehaupt: research idea, hypothesis, experimental design, contributed substantially to discussion and writing of the paper, and proofread the manuscript.

\section{References}

Alves KM, Pessan JP, Brighenti FL, Franco KS, Oliveira FA, Buzalaf MA, et al. In vitro evaluation of the effectiveness of acidic fluoride dentifrices. Caries Res. 2007;41(4):263-7.

Amaechi BT, Higham SM, Edgar WM. Factors affecting the development of carious lesions in bovine teeth in vitro. Arch Oral Biol. 1998 Aug;43(8):619-28.

Becker K, Engler K, Trakiniené G, Attin T, Attin R. Advanced transversal microradiography enables single section demineralization experiments. Measurement. 2020; 149: 149106999.

Brighenti FL, Delbem AC, Buzalaf MA, Oliveira FA, Ribeiro DB, Sassaki KT. In vitro evaluation of acidified toothpastes with low fluoride content. Caries Res. 2006;40(3):239-44.

Buzalaf MA, Pessan JP, Honório HM, Ten Cate JM. Mechanisms of action of fluoride for caries control. Monogr Oral Sci. 2011;22:97-114.

Buzalaf MA, Whitford GM. Fluoride metabolism. Monogr Oral Sci. 2011;22:20-36.

Enax J, Epple M. Synthetic hydroxyapatite as a biomimetic oral care agent. Oral Health Prev Dent. 2018;16(1):7-19.

Esteves-Oliveira M, Santos NM, Meyer-Lueckel $\mathrm{H}$, Wierichs RJ, Rodrigues JA. Caries-preventive effect of anti-erosive and nano-hydroxyapatite-containing toothpastes in vitro. Clin Oral Investig. 2017 Jan;21(1):291-300.

Forsback AP, Areva S, Salonen JI. Mineralization of dentin induced by treatment with bioactive glass S53P4 in vitro. Acta Odontol Scand. $2004 \mathrm{Feb} ; 62(1): 14-20$.

Geurtsen W, Hellwig E, Klimek J et al. Caries prevention in permanent teeth - basic recommendations. S2k Guideline. Register No. 083021. AWMF Online; 2016.

Gmür R, Giertsen E, van der Veen MH, de Josselin de Jong E, ten Cate JM, Guggenheim B. In vitro quantitative light-induced fluorescence to measure changes in enamel mineralization. Clin Oral Investig. 2006 Sep;10(3):187-95.

Hellwig E, Klimek J, Ganß C. Hydroxylapatit in Zahnpasten: Wirkt es oder wirkt es nicht. zm online. 2018;22:32-44.

Hench LL. Bioceramics: from concept to clinic. J Am Ceram Soc. 1991;74(7):1487-510.

Hench LL. The story of Bioglass. J Mater Sci Mater Med. 2006 Nov; 17(11):967-78.
Huang S, Gao S, Cheng L, Yu H. Combined effects of nano-hydroxyapatite and Galla chinensis on remineralisation of initial enamel lesion in vitro. J Dent. 2010 Oct;38(10):811-9.

Huang S, Gao S, Cheng L, Yu H. Remineralization potential of nano-hydroxyapatite on initial enamel lesions: an in vitro study. Caries Res. 2011;45(5):460-8.

Kielbassa AM, Shohadai SP, Schulte-Mönting J. Effect of saliva substitutes on mineral content of demineralized and sound dental enamel. Support Care Cancer. 2001 Jan;9(1):40-7.

Klimek J, Hellwig E, Ahrens G. Effect of plaque on fluoride stability in the enamel after amine fluoride application in the artificial mouth. Dtsch Zahnarztl Z. 1982 Oct;37(10):836-40. German.

Lagerweij MD, van Loveren C. Declining caries trends: are we satisfied. Curr Oral Health Rep. 2015;2(4):212-7.

Li L, Pan H, Tao J, Xu X, Mao C, Gu X, et al. Repair of enamel by using hydroxyapatite nanoparticles as the building blocks. J Mater Chem. 2008;18(34):4079-84.

Li X, Wang J, Joiner A, Chang J. The remineralisation of enamel: a review of the literature. J Dent. 2014 Jun;42(suppl 1S):12-20.

Lippert F, Juthani K. Fluoride dose-response of human and bovine enamel artificial caries lesions under $\mathrm{pH}$-cycling conditions. Clin Oral Investig. 2015 Nov;19(8):1947-54.

Makeeva IM, Polyakova MA, Avdeenko OE, Paramonov YO, Kondrat'ev SA, Pilyagina AA. Effect of long term application of toothpaste Apadent Total Care Medical nano-hydroxyapatite. Stomatologia. 2016;95(4):34-6. Russian.

Manchery N, John J, Nagappan N, Subbiah GK, Premnath P. Remineralization potential of dentifrice containing nanohydroxyapatite on artificial carious lesions of enamel: a comparative in vitro study. Dent Res J. 2019 Sep; 16(5):310-7.

Meyer F, Amaechi BT, Fabritius HO, Enax J. Overview of calcium phosphates used in biomimetic oral care. Open Dent J. 2018 May; 12(1):406-23.

Milly H, Festy F, Watson TF, Thompson I, Banerjee A. Enamel white spot lesions can remineralise using bio-active glass and polyacrylic acid-modified bio-active glass powders. J Dent. 2014 Feb;42(2):158-66.

Pohlert T. The pairwise multiple comparison of mean ranks package (PMCMR). R package. 2014. http://CRAN.R- project.org/package= PMCMR.

R Core Team. R: a language and environment for statistical computing. R Foundation for Statistical Computing. 2015, https://www.Rproject.org/.

Schlagenhauf U, Kunzelmann KH, Hannig C, May TW, Hösl H, Gratza M, et al. Impact of a non-fluoridated microcrystalline hydroxyapatite dentifrice on enamel caries progression in highly caries-susceptible orthodontic patients: a randomized, controlled 6-month trial. J Investig Clin Dent. 2019 May;10(2): e12399.

Selwitz RH, Ismail AI, Pitts NB. Dental caries. Lancet. 2007 Jan;369(9555):51-9.

Shellis RP, Ganss C, Ren Y, Zero DT, Lussi A. Methodology and models in erosion research: discussion and conclusions. Caries Res. 2011; 45(suppl 1):69-77.

Wefel JS. NovaMin: likely clinical success. Adv Dent Res. 2009;21(1):40-3.

Wegehaupt FJ, Tauböck TT, Stillhard A, Schmidlin PR, Attin T. Influence of extra- and intraoral application of CPP-ACP and fluoride on re-hardening of eroded enamel. Acta Odontol Scand. 2012 May;70(3):177-83.

White DJ. The application of in vitro models to research on demineralization and remineralization of the teeth. Adv Dent Res. 1995 Nov; 9(3):175-93

Wickham H. ggplot2: elegant graphics for data analysis. New York: Springer; 2016.

Wierichs RJ, Zelck H, Doerfer CE, Appel P, Paris $S$, Esteves-Oliveira M, et al. Effects of dentifrices differing in fluoride compounds on artificial enamel caries lesions in vitro. Odontology. 2017 Jan;105(1):36-45.

Yamazaki H, Margolis HC. Enhanced enamel remineralization under acidic conditions in vitro. J Dent Res. 2008 Jun;87(6):569-74.

Zhang M, He LB, Exterkate RA, Cheng L, Li JY, Ten Cate JM, et al. Biofilm layers affect the treatment outcomes of $\mathrm{NaF}$ and Nano-hydroxyapatite. J Dent Res. 2015 Apr;94(4): $602-7$. 